\title{
Correlation between chemosensitivity and mRNA expression level of 5-fluorouracil-related metabolic enzymes during liver metastasis of colorectal cancer
}

\author{
KENJI OKUMURA, HISANORI SHIOMI, EIJI MEKATA, MACHIKO KAIZUKA, \\ YOSHIHIRO ENDO, YOSHIMASA KURUMI and TOHRU TANI
}

Department of Surgery, Shiga University of Medical Science, Seta-tsukinowa-cho, Otsu, Shiga 520-2192, Japan

Received September 13, 2005; Accepted November 2, 2005

\begin{abstract}
The attainment of chemoresistance during tumor metastasis is often experienced. In this study, we evaluated the correlation between sensitivity to 5-fluorouracil (5-FU) and the mRNA expression level of several 5-FU-related metabolic enzymes [thymidylate synthase, dihydropyrimidine dehydrogenase (DPD), thymidylate phosphorylase (TP), orotate phosphoribosyl transferase, and uridine phosphorylase] in primary colorectal cancer and synchronous liver metastases from ten patients to investigate how colorectal cancer acquires 5-FU resistance during liver metastases. A liver metastasis model of xenotransplanted human colon cancer cell line (HCT116) in nude mice and several cell lines from metastatic liver tumors were also established and analyzed. Chemosensitivity and mRNA expression levels were measured by using collagen gel droplet-embedded culture drug sensitivity tests and real-time quantitative reverse transcriptionpolymerase chain reaction. Metastatic liver tumors were significantly more resistant to 5-FU than primary colorectal cancer $(\mathrm{T} / \mathrm{C}, 88.7 \%$ versus $69.7 \%, \mathrm{p}<0.05)$. DPD and TP mRNA levels were significantly higher in metastatic liver tumors (DPD: $10.36 \pm 1.81$ versus $3.95 \pm 0.99, \mathrm{p}<0.01$; and TP: $18.80 \pm 4.96$ versus $7.28 \pm 1.23, \mathrm{p}<0.05)$ and inversely correlated with 5-FU sensitivity (DPD: $\mathrm{R}=0.570$, $\mathrm{p}<0.05$; TP: $\mathrm{R}=0.600, \mathrm{p}<0.05)$. In the mouse model, metastatic liver tumors were significantly more resistant to 5 -FU than HCT116 (T/C, 92.7\%, 96.2\% versus 68\%, p<0.001). The DPD and TP mRNA levels increased with repeated liver metastases. DPD and TP may affect the acquisition of resistance to 5-FU during liver metastasis of colorectal cancer. This mouse model may be useful for analyzing the mechanisms of how colorectal cancer acquires resistance to 5-FU during liver metastases.
\end{abstract}

Correspondence to: Dr Hisanori Shiomi, Department of Surgery, Shiga University of Medical Science, Seta-tsukinowa-cho, Otsu, Shiga 520-2192, Japan

E-mail:shiomi@belle.shiga-med.ac.jp

Key words: colorectal cancer, liver metastasis, 5-FU metabolic enzymes, 5-FU resistance, mouse model

\section{Introduction}

5-Fluorouracil (5-FU) has been used for more than 40 years to treat various cancers and is still used as a first-line anticancer drug for colorectal carcinoma (1). Although the response rate as a single agent is usually less than $20 \%$, biochemical modulation by leucovorin enhanced the anticancer effects of 5-FU and increased its response rate to 20-30\% (2). Irinotecan, a topoisomerase-I inhibitor, showed a higher response rate of nearly $40 \%$ when it was used with 5-FU and leucovorin for the treatment of metastatic colorectal cancer (3). These facts suggest that it is important to understand the mechanism of the antitumor effect of 5-FU and determine how metastatic tumors acquire resistance to this anticancer drug to improve the response rate to 5-FU.

Several 5-FU-related metabolic enzymes are thought to correlate with the sensitivity to 5-FU (4-10). Two main modes of action have been proposed for 5-FU through its active metabolites, 5-fluoro-2'deoxyuridine-5'-monophosphate (FdUMP) and 5-fluoro-uridine-5'-triphosphate (FUTP) (10). FdUMP suppresses thymidylate synthase (TS) by forming a covalent ternary complex with 5,10-methylenetetrahydrofolate and thus indirectly affects DNA synthesis (11). Therefore, the expression levels of TS have been thought to correlate with sensitivity to 5-FU. FUTP is incorporated into cellular RNA, resulting in RNA dysfunction (12). 5-FU is catabolized to 2 -fluoro- $\beta$-alanine in the liver and other tissues by dihydropyrimidine dehydrogenase (DPD). DPD, which is the first and rate-limiting enzyme, rapidly eliminates more than $85 \%$ of administered 5-FU $(13,14)$. This catabolism has been thought to have a meaningful role in resistance to 5-FU. To activate 5-FU into its nucleotides, three phosphorylation pathways and enzymes are known (15). Thymidylate phosphorylase (TP) indirectly metabolizes 5-FU to FdUMP by 5-fluoro-2'-deoxyuridine (FUdR). 5-FU is directly metabolized to 5-fluorouridine-5'-monophosphate (FUMP) in a reaction by orotate phosphoribosyl transferase (OPRT). Uridine phosphorylase (UP) indirectly metabolizes 5-FU to FUMP in a sequence of reactions that converts 5-FU to 5-fluororidine.

In gastric and colorectal cancers, high expression levels of TS mRNA and protein were correlated with unresponsiveness to 5-FU (4). In colorectal cancers, low levels of DPD mRNA expression were seen in all of the 5-FU responders compared 
Table I. Patient and tumor characteristics.

\begin{tabular}{cccccccc}
\hline Case & Age (years) & Sex & Location of tumor & Differentiation & T & N & M \\
\hline 1 & 63 & F & Sigmoid colon & Well & T3 & N0 & M1 \\
2 & 67 & F & Sigmoid colon & Moderate & T3 & N1 & M1 \\
3 & 68 & F & Sigmoid colon & Moderate & T3 & N2 & M1 \\
4 & 65 & M & Rectum & Well & T3 & N1 & M1 \\
5 & 53 & M & Sigmoid colon & Moderate & T3 & N0 & M1 \\
6 & 76 & F & Rectum & Moderate & T4 & N0 & M1 \\
7 & 79 & F & Ascending colon & Moderate & T2 & N1 & M1 \\
8 & 36 & F & Sigmoid colon & Endocrine & T3 & N0 & M1 \\
9 & 63 & F & Ascending colon & Moderate & T3 & N2 & M1 \\
10 & 64 & M & Sigmoid colon & Well & T3 & N0 & M1 \\
\hline
\end{tabular}

TNM were categorized according to TNM 2002 classification in colorectal carcimoma.

A

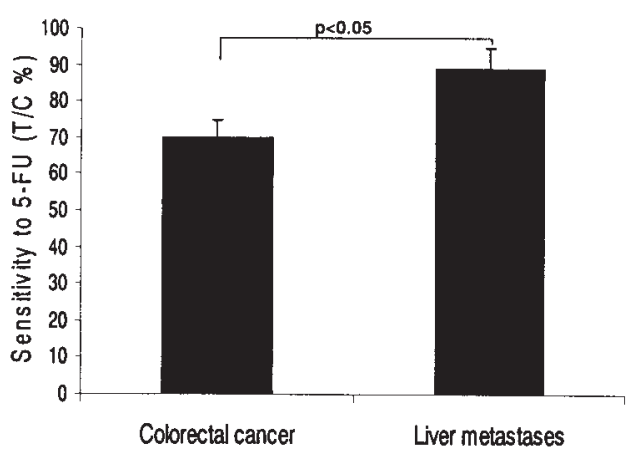

B

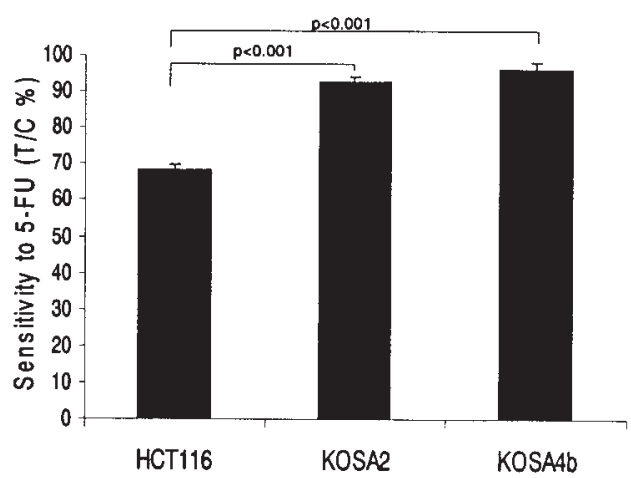

Figure 1. Sensitivity to 5-FU measured by CD-DST method (5-FU concentration $1.0 \mu \mathrm{g} / \mathrm{ml}, 24 \mathrm{~h}$ exposure) of clinical samples and cell lines. (A) Sensitivity to 5-FU of colorectal cancer and synchronous liver metastases from 10 patients. Metastatic liver tumors were significantly more resistant to 5-FU than the primary colorectal cancer (T/C, 88.7\% versus $69.7 \%, \mathrm{p}<0.05)$. (B) Sensitivity to 5-FU of xenotransplated human colon cancer cell line (HCT116) and liver metastases (KOSA2 and KOSA4b). The KOSA2 and KOSA4b cell lines derived from metastatic liver tumor were significantly more resistant to 5-FU than

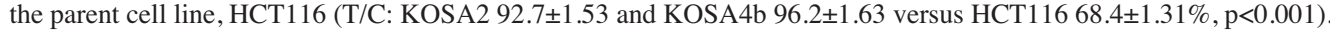

with much higher levels in the 5-FU nonresponders (5). A few studies demonstrated that high levels of TP mRNA correlated with resistance to 5-FU $(5,6)$. Recently, 5-FUsensitive colorectal cancer tissues were found to have higher OPRT enzyme activity than nonsensitive tissues, as determined by an in vitro chemosensitivity test (7). Colon tumor cell lines with inhibited UP showed less cytotoxicity to 5-FU (8).

It is often observed that malignant tumors acquire chemoresistance during metastasis or show different clinical responses to chemotherapy at different sites of metastasis (9). Some reports indicate that the sensitivity to antitumor drugs, as determined by several sensitivity tests, differed between the primary tumors and their metastatic cancers (16-18). Several reports have shown that the expression levels of 5-FU-related metabolic enzymes differed from the sites of metastases (9,19-21). However, no previous reports have compared the sensitivity and expression level of 5-FU-related metabolic enzymes in the primary tumor and its metastatic tumors in order to discuss the attainment of resistance or low sensitivity to 5-FU during tumor metastasis.

In this study, to clarify the mechanism of acquisition of resistance to 5-FU during liver metastasis of colorectal cancer, we investigated the correlation between the expression levels of TS, DPD, TP, OPRT, and UP mRNA and the sensitivity to 5 -FU of primary colorectal cancer and synchronous liver metastases. We found that the expression levels of DPD and TP mRNA were higher in liver metastases than in primary colorectal cancer and correlated with lower sensitivity to 5-FU. To confirm this result from clinical specimens, we created a liver metastasis model of a xenotransplanted human colon cancer cell line, HCT116, in nude mice. We established several cell lines highly metastasizing to the liver. HCT116, established from a primary cell culture of a human colonic carcinoma (22), is known to be sensitive to 5-FU (23). HCT116 highly metastasizes to the liver when it is injected into the subserosa of the cecum in nude mice (24). Cell lines that were established from liver metastases were also analyzed and showed higher expression levels of DPD and TP mRNA, as well as lower sensitivity to 5-FU compared with the parent cell line, HCT116.

\section{Materials and methods}

Collection of tumor tissues. Tumor tissues were collected from surgically resected primary colorectal cancer and synchronous liver metastases from 10 patients between September 2001 and October 2004 at the Department of 
A

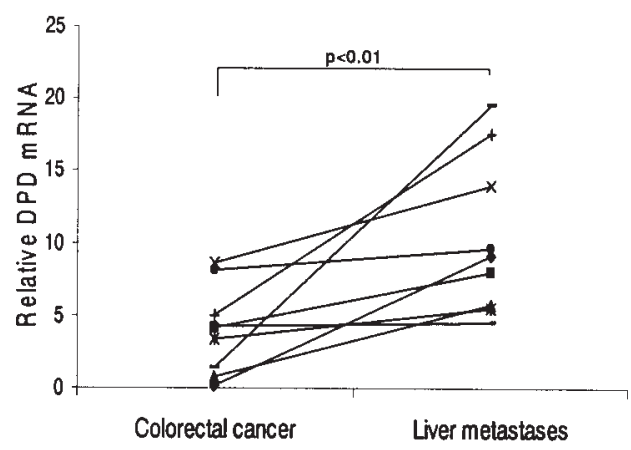

C

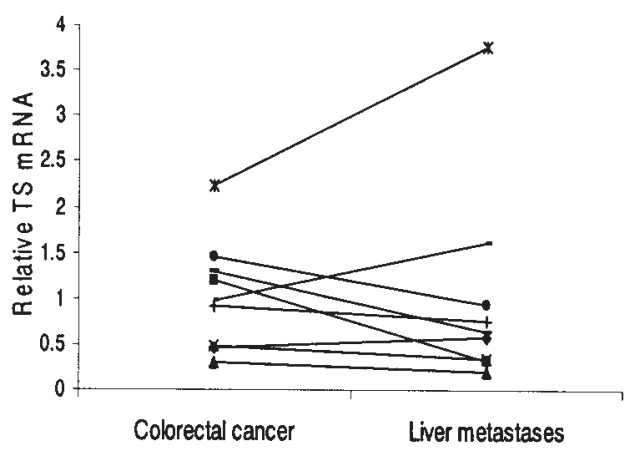

$\mathbf{E}$

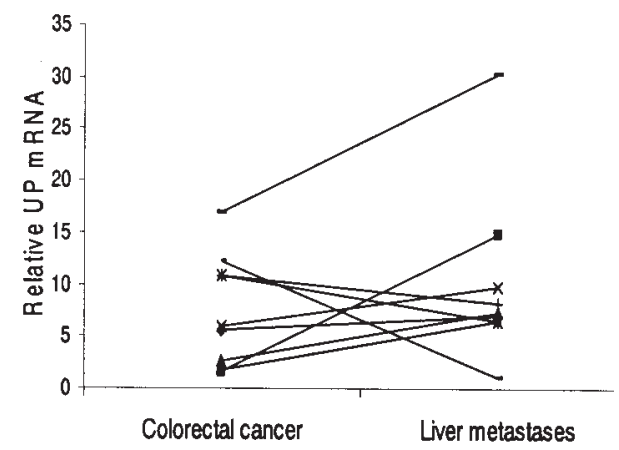

Surgery, Shiga University of Medical Science, Shiga, Japan. Clinicopathological features of the 10 patients who participated in this study are listed in Table I. Briefly, two patients had rectal cancer, three patients were men, the average age was 65 years, and all patients had synchronous liver metastases. None of the patients received preoperative treatment.

The samples were immediately cut into pieces. One portion was snap-frozen in liquid nitrogen and stored at $-80^{\circ} \mathrm{C}$ until the extraction of RNA, and the other portion was preserved in culture medium at $4^{\circ} \mathrm{C}$ until sensitivity tests were performed. This study was approved by the Institutional Review Board of Shiga University of Medical Science. All patients gave their written consent.

Real-time quantitative reverse transcription-polymerase chain reaction $(R T-P C R)$. Total RNA was extracted using Trizol reagent (Invitrogen, Inc, Carlsbad, CA), an RNeasy Mini kit (Qiagen, Inc., Chatsworth, CA) and DNA-free (Ambion, Inc., Austin, TX) according to the manufacturers' instructions. The purity and amount of total RNA were spectrophotometrically estimated by measuring the absorbance of an aliquot at 260 and $280 \mathrm{~nm}$. The integrity of the rRNA bands was checked using agarose gel electrophoresis. Prepared total RNA $(1 \mu \mathrm{g})$ was reverse-transcribed to synthesize cDNA using the
B
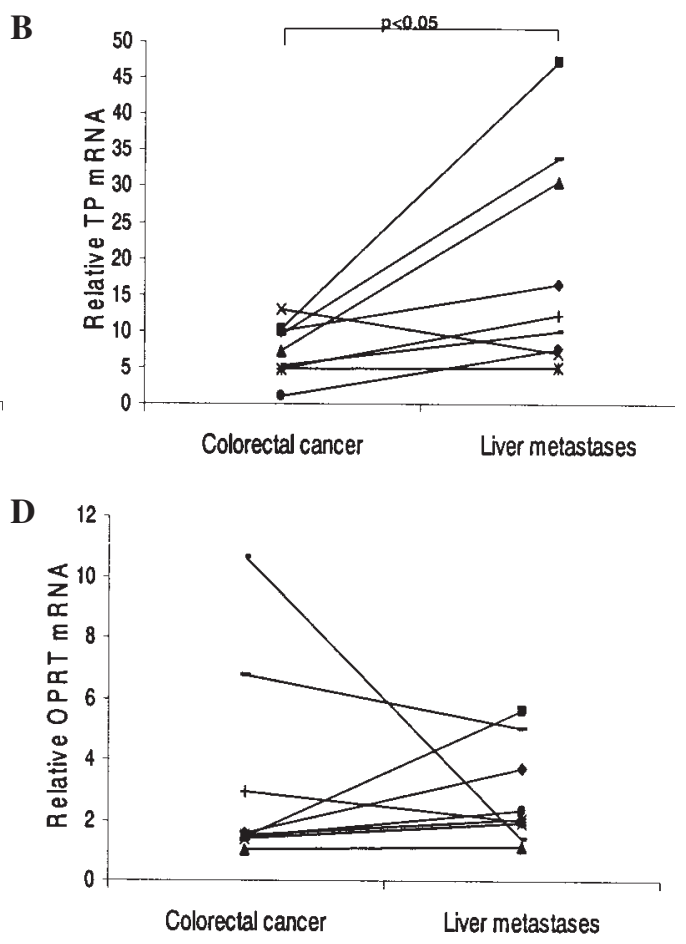

Figure 2. The expression level of DPD, TP, TS, OPRT, and UP mRNA in nine paired colorectal cancers and synchronous liver metastases (A-E). The expression level of DPD and TP mRNA were significantly higher in metastatic liver tumors than in primary colorectal cancer. (A) DPD, 10.36 versus $3.95, \mathrm{p}<0.01$. (B) $\mathrm{TP}, 18.80$ versus $7.28, \mathrm{p}<0.05$.

oligo $(\mathrm{dT})_{12-18}$ primer and Superscript II (Invitrogen, Inc, Carlsbad, CA) according to the manufacturer's instructions. Expression levels of TS, DPD, TP, OPRT, and UP mRNA were measured by real-time quantitative RT-PCR (LightCycler; Roche Diagnostics GmbH, Mannheim, Germany) and LightCycler mRNA Quantification Plus kit for TS, DPD, and TP mRNA (Roche Diagnostics $\mathrm{GmbH}$ ) according to the manufacturer's instructions. The PCR reaction mixture for OPRT and UP mRNA consisted of $500 \mathrm{nM}$ of each primer, $4 \mathrm{mM} \mathrm{MgCl}_{2}$, and $1 \mu 1$ LightCycler-FastStart DNA Master SYBR-Green (Roche Diagnostics $\mathrm{GmbH}$ ) to a final volume of $20 \mu 1$. The sequences and annealing temperatures were: OPRT, 5'-TCCTGGGCAGATCTAGTAAATGC-3' and 5'TGCTCCTCAGCCATTCTAACC- $3^{\prime}$ at $55^{\circ} \mathrm{C}$; and UP, 5'TGACTGCCCAGGTAGAGACTATCC- $3^{\prime}$ and $5^{\prime}$-AGA CCTATCCCACCAGAAGTGC-3' at $60^{\circ} \mathrm{C}$, followed by 40 cycles. The G6PDH Primer Set was obtained from Search LC GmbH (Heidelberg, Germany) and used as an internal control.

Collagen gel droplet-embedded culture drug sensitivity test $(C D-D S T)$. Chemosensitivity to 5-FU was analyzed using the CD-DST method according to the manufacturer's instructions $(25,26)$. Briefly, each sample was treated with Dispersion Enzyme Cocktail EZ (Nitta Gelatin Inc., Osaka, Japan). The obtained cell suspension was inoculated into collagen-coated flasks (CG-flask, Nitta Gelatin Inc.) and cultured in preculture 
$\mathbf{A}$

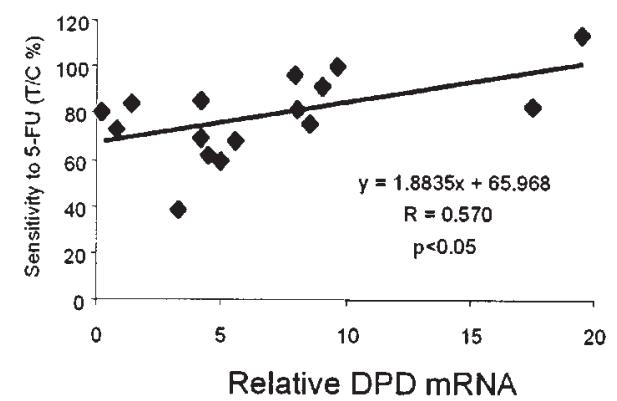

C

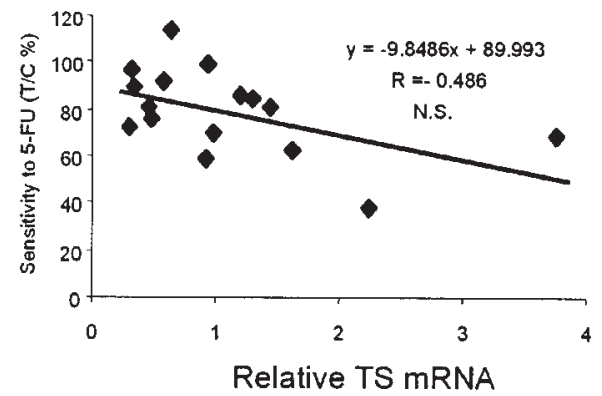

$\mathbf{E}$

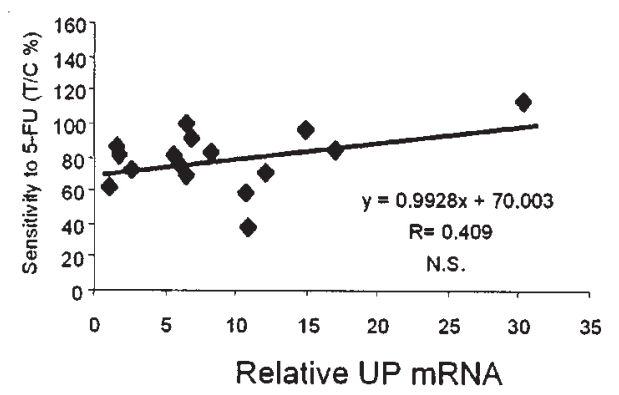

medium (PCM-1) at $37^{\circ} \mathrm{C}$ overnight. Collagen gel was digested with Dispersion Enzyme Cocktail EZ, and viable cancer cells were obtained. The prepared cancer cell suspension was added to a collagen solution (Collagen Gel Culture Kit, Nitta Gelatin Inc.) with a final density of $1 \times 10^{5}$ cells $/ \mathrm{ml}$. Three drops of the collagen-cell mixture $(30 \mu 1 /$ droplet $)$ were placed in each well of 6-well plates on ice and allowed to gel at $37^{\circ} \mathrm{C}$ in a $\mathrm{CO}_{2}$ incubator. DF medium containing $10 \%$ fetal bovine serum was overlaid on each well $1 \mathrm{~h}$ later and incubated overnight.

5-FU was purchased from Kyowa Hakko Kogyo, Co., Ltd. (Tokyo, Japan). 5-FU was added to the medium at a final concentration of $1.0 \mu \mathrm{g} / \mathrm{ml}$, and the plates were incubated for $24 \mathrm{~h}$. After the removal of medium containing 5-FU, each well was rinsed twice with $3 \mathrm{ml}$ of Hank's balanced salt solution, overlaid with $4 \mathrm{ml}$ of PCM-2 medium (serum-free medium, Nitta Gelatin Inc.), and incubated for an additional 7 days. At the end of incubation, neutral red was added to each well at a final concentration of $50 \mu \mathrm{g} / \mathrm{ml}$, and colonies of cancer cells in the collagen gel droplets were stained for $2 \mathrm{~h}$. Each collagen droplet was fixed with $10 \%$ neutral-buffered formalin, washed in water, air-dried, and quantified by image analysis. The growth rates of control incubations were calculated as the image density on day 7 divided by the image density on day 1 . Cases with growth rates $>0.8$ were regarded as evaluable cases. The in vitro sensitivity was expressed as the $\mathrm{T} / \mathrm{C}$ ratio percentage, where $\mathrm{T}$ was the image optical density of the treated group and $\mathrm{C}$ was that of the control.
B

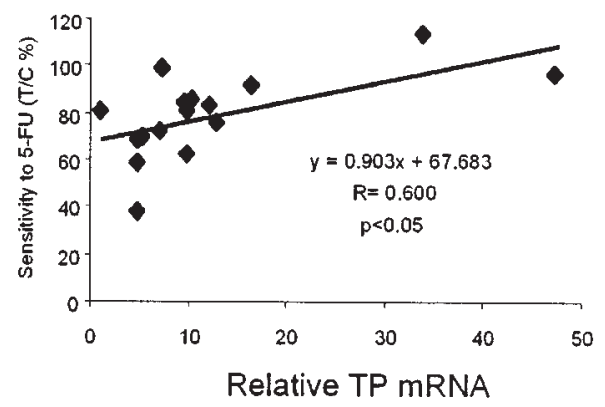

D

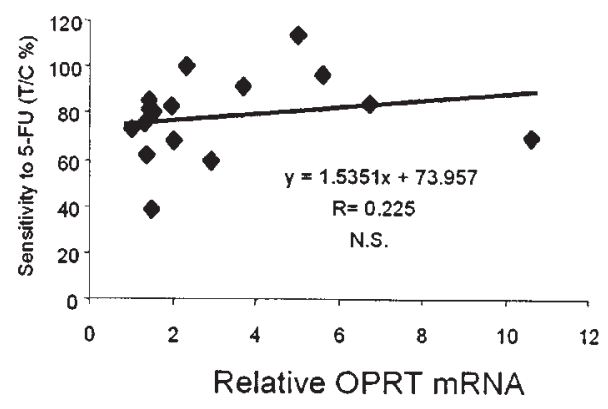

Figure 3. Correlation between the expression level of DPD, TP, TS, OPRT, and UP mRNA and sensitivity to 5-FU (A-E) of colorectal cancer and synchronous liver metastases. The expression level of DPD and TP mRNA were significantly and inversely correlated with sensitivity to 5-FU. (A) DPD, $R=0.570, p<0.05$. (B) $T P, R=0.600$, $p<0.05$.

Human tumor xenograft and nude mouse liver metastasis model. Male nude mice with a BALB/cA genetic background were purchased from CLEA, Inc (Tokyo, Japan). The 6- to 8week-old mice weighing 20-22 g were used. HCT116 was obtained from the American Type Culture Collection (MD, USA) and cultured according to the manufacturer's instructions. A liver metastasis model of xenotransplanted human colon cancer cells in nude mice was developed according to previous studies $(27,28)$. A single cell suspension of HCT116 (5.0x106/50 $\mu 1)$ in PBS was injected subcutaneously into nude mice. After tumors reached the exponential growth phase, they were resected aseptically, and viable tumor tissues were minced into 3- to 5-mm diameter pieces in PBS. Mice were anesthetized with diethyl ether, and an incision was made through the left lower abdominal pararectal line and peritoneum. The cecum wall was carefully exposed and a tumor piece was then fixed on the serosa of the cecum with a 5-0 Dexon (Davis-Geck, Inc., Manati, PR) transmural suture. The cecum was then returned to the peritoneal cavity, and the abdominal wall and skin were closed with 5-0 Dexon sutures. The mice were sacrificed after 6 weeks, and metastatic liver tumors were extracted. Half of the extracted tumors were cut into 3- to 5-mm diameter pieces in PBS and sutured on the serosa of the cecum of another mice in the same way. The other pieces were minced and cultured in $10-\mathrm{cm}$ dishes with RPMI-1640 containing 10\% FBS. We established several cell lines from this model (the second cell line was named KOSA2, and the fourth was named KOSA4b), and analyzed the expression levels of TS, DPD, TP, OPRT, and UP mRNA and chemosensitivity to 5-FU as described above. 
A

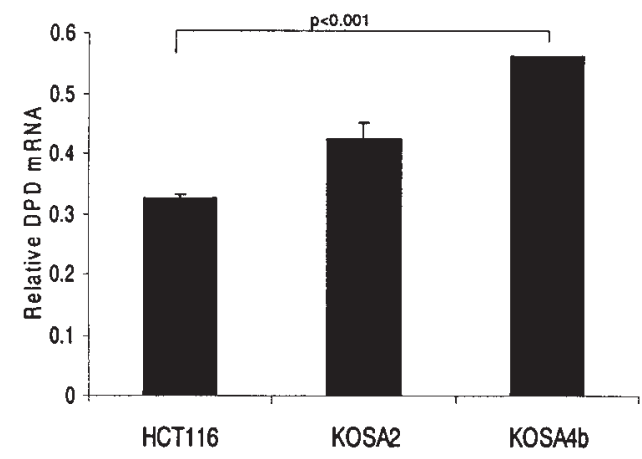

C

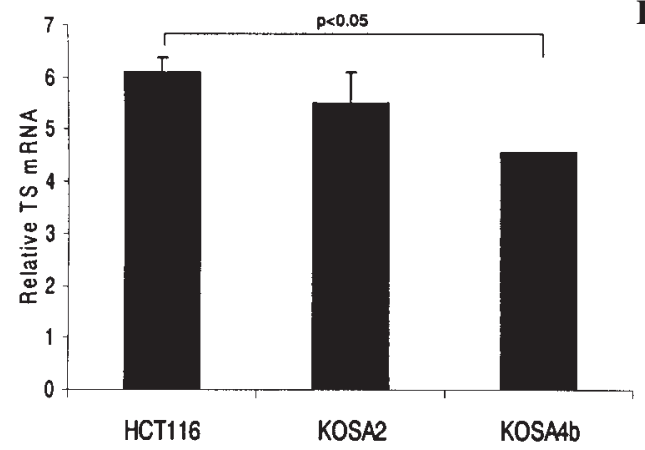

$\mathbf{E}$

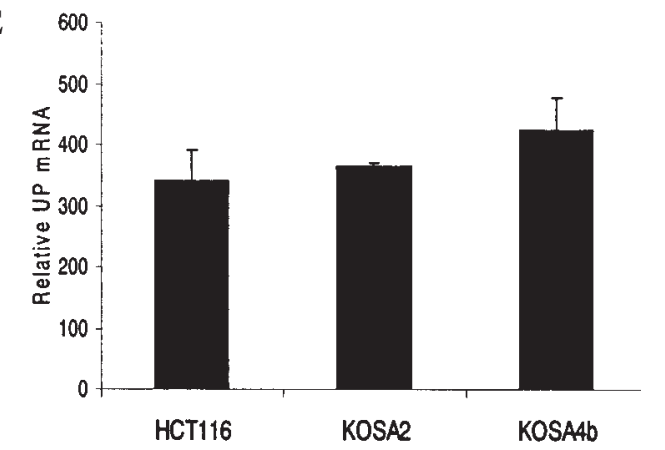

Statistical analysis. The Wilcoxon signed-rank test was used to compare sensitivity to 5-FU of primary colorectal cancer and synchronous liver metastases. The Student's t-test was used to compare each mRNA expression level. Linear regression analysis was used to evaluate the correlation between sensitivity to 5-FU and mRNA expression level of 5-FU-related metabolic enzymes. Statistical significance was established at the $\mathrm{p}<0.05$ level for each analysis.

\section{Results}

CD-DST was performed in all colorectal cancer tissue (efficacy, 100\%) and 8 of 10 liver metastases (efficacy, 80\%) specimens. Metastatic liver tumors were significantly more resistant to 5 -FU than the primary colorectal cancer $(\mathrm{T} / \mathrm{C}$, $88.7 \%$ versus $69.7 \%$, p<0.05) (Fig. $1 \mathrm{~A}$ ).

The quality of mRNA isolated from 9 of 10 samples could be used for further RT-PCR analysis. The expression level of DPD mRNA was significantly higher in metastatic liver tumors compared with primary colorectal cancer (mean \pm SE, $10.36 \pm 1.81$ versus $3.95 \pm 0.99$, p $<0.01$; Fig. $2 \mathrm{~A}$ ) and inversely correlated with sensitivity to $5-\mathrm{FU}(\mathrm{R}=0.570$, $\mathrm{p}<0.05$; Fig. 3A). The expression level of TP mRNA was also significantly higher in metastatic liver tumors
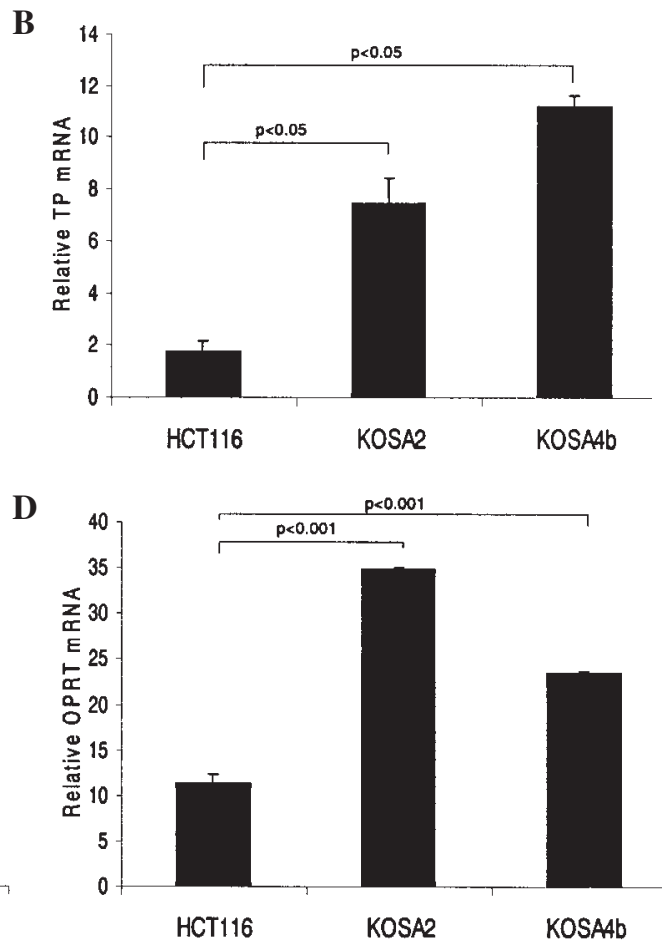

Figure 4. The expression level of DPD, TP, TS, OPRT, and UP mRNA (A-E) of xenotransplated human colon cancer cell line (HCT116) and liver metastases (KOSA2 and KOSA4b). The expression level of DPD and TP mRNA increased with repeated metastases compared with parent cell line, HCT116. (A) DPD: HCT116 0.325 \pm 0.005 , KOSA2 $0.425 \pm 0.025$ and KOSA4b $0.56 \pm 0.0$; and (B) TP: $1.71 \pm 0.42,7.49 \pm 0.92$, and $11.19 \pm 0.42$, respectively.

$(18.80 \pm 4.96$ versus $7.28 \pm 1.23, \mathrm{p}<0.05$; Fig. $2 \mathrm{~B})$ and inversely correlated with sensitivity to $5-\mathrm{FU}(\mathrm{R}=0.600$, $\mathrm{p}<0.05$; Fig. 3B). The expression level of TS mRNA was not significantly different between metastatic tumors and primary tumors $(1.02 \pm 0.37$ versus $1.03 \pm 0.20, \mathrm{p}=0.966$; Fig. $2 \mathrm{C})$, and did not correlate with sensitivity to $5-\mathrm{FU}(\mathrm{R}=-0.486$, $\mathrm{p}=0.056$; Fig. $3 \mathrm{C})$. The expression level of OPRT mRNA was lower and that of UP mRNA was higher in metastatic liver tumors; however, there were no significant changes when compared with primary tumors (OPRT: $2.79 \pm 0.54$ versus $3.18 \pm 1.10, \mathrm{p}=0.758$, Fig. 2D; and UP: $10.1 \pm 2.79$ versus $7.56 \pm 1.78, \mathrm{p}=0.448$, Fig. 2E), and there was no correlation with sensitivity to 5-FU (OPRT: $\mathrm{R}=0.225, \mathrm{p}=0.401$, Fig. 3D; and UP: $\mathrm{R}=0.409$, $\mathrm{p}=0.116$, Fig. $3 \mathrm{E})$.

In the nude mouse liver metastasis model, the KOSA2 and KOSA4b cell lines derived from the metastatic liver tumor were significantly more resistant to 5 -FU than the parent cell line, HCT116 (T/C: KOSA2 92.7 \pm 1.53 , KOSA4b 96.2 \pm 1.63 versus HCT116 68.4 $1.31 \%, \mathrm{p}<0.001$; Fig. 1B). The expression levels of DPD and TP mRNA increased with repeated metastases compared with HCT116 (DPD: HCT116 $0.325 \pm 0.005$, KOSA2 $0.425 \pm 0.025$, and KOSA4b $0.56 \pm 0.0$, Fig. 4A; and TP: $1.71 \pm 0.42,7.49 \pm 0.92$, and $11.19 \pm 0.42$, respectively, Fig. 4B). The expression level of TS mRNA decreased with repeated metastases $(6.09 \pm 0.30,5.51 \pm 0.61$, and $4.55 \pm 0.015$, respectively) (Fig. 4C). The expression levels of OPRT and UP mRNA were higher in metastatic liver 
tumors (OPRT: $11.3 \pm 1.05,34.9 \pm 0.16$, and $23.5 \pm 0.24$, respectively, Fig. 4D; and UP: $339 \pm 51.11,365 \pm 3.71$, and $424 \pm 54.39$, respectively, Fig. 4E).

\section{Discussion}

We often observe that different sites of metastasis show different clinical responses to chemotherapy. However, the mechanism behind the acquisition of different sensitivity levels by tumor cells during metastases is not well known. Several 5-FU-related metabolic enzymes have been studied, and their intratumoral expression levels are thought to correlate with sensitivity to 5-FU $(4-10,19)$. Some reports have indicated that the expression levels of 5-FU metabolic enzymes differed between the primary and metastatic sites $(20,21)$.

In this study, we focused on 5-FU-related metabolic enzymes. We investigated how colorectal cancer became resistant to 5-FU during liver metastasis by comparing the expression levels of 5-FU-related metabolic enzymes and the sensitivity to 5-FU of primary colorectal cancer and synchronous liver metastases. We found that two 5-FUrelated metabolic enzymes, DPD and TP, might affect the acquisition of resistance to 5-FU during liver metastasis of colorectal cancer. The expression levels of DPD and TP mRNA were significantly higher in metastatic liver tumor compared with primary colorectal cancer, and the levels were significantly and inversely correlated with sensitivity to 5-FU. Several studies reported that 5-FU catabolism by DPD was a probable determining factor for resistance to 5-FU $(5,10,15)$ and the expression level of TP correlated with resistance to $5-\mathrm{FU}(5,6)$. Results from the present study correspond with previous reports that tumors with higher expression levels of DPD or TP mRNA showed low sensitivity to 5-FU for colorectal cancer (5). Because intratumoral expression levels of DPD and TP mRNA are high, DPD inhibitors, such as 5-chloro-2,4-dihidroxypyrimidine (29) and capecitabine (30), which is designed to generate 5-FU selectively in tumors by TP, might be useful for chemotherapy to treat metastatic liver cancer derived from colorectal cancer.

Several reports have indicated that TS expression was significantly related to the response to 5-FU in gastric and colorectal cancer patients and high intratumoral expression of TS mRNA or protein was one cause of resistance to 5-FU (4). In the present study, however, the TS mRNA level did not differ between metastatic liver tumors and primary colorectal cancer, and did not correlate with sensitivity to 5 -FU in both the clinical samples and animal model. Previous reports have indicated that the expression level of TS mRNA or protein in liver metastases is significantly lower than that of primary colorectal cancer $(20,21)$. These reports also indicate that TS might not influence the acquisition of resistance to 5-FU during liver metastases of colorectal cancer. From these results, we can understand why liver metastases of colorectal cancer have a high response rate to hepatic arterial infusion of 5-FU (1). A high dose of 5-FU may be enough to not be degraded by a high expression level of DPD, and a low expression level of TS assists 5-FU in inhibiting DNA synthesis in tumors. However, in patients treated by 5-FU who had liver metastases from colorectal cancer, TS amplification was identified and thought to be a mechanism of resistance to 5-FU (31). Acquired 5-FU resistance after 5-FU treatment in liver metastases of colorectal cancer seems to be associated with increased TS expression.

The preferential use of the OPRT pathway was revealed to correlate with a higher sensitivity to 5-FU in human colorectal tumors and normal mucosa (32). Some investigators stated that UP was critical to the activation of 5-FU in experimental models (33). However, OPRT and UP did not appear to affect 5-FU resistance during liver metastases of colorectal cancer. In this study, the expression levels of OPRT mRNA and UP mRNA did not differ between metastatic liver tumors and primary colorectal cancer, and the expression level of mRNA did not correlate with sensitivity to 5-FU.

Because the number of clinical specimens was limited, we made a liver metastasis model of xenotransplanted human colon cancer cells (HCT116) in nude mice. We established and analyzed several cell lines from metastatic liver tumors. In this model, liver metastasis cells were significantly more resistant to 5-FU than parent HCT116 cells. The expression level of DPD and TP mRNA in metastatic cells increased with repeated metastases. McLeod et al performed an analysis of DPD activity in colorectal cancer, including 60 primary tumor and 3 liver metastasis specimens, and 5 colorectal cell lines (34). They reported that the median DPD activity in cell lines was lower than that of colorectal tumors or liver metastases. In the present study, the expression level of DPD mRNA in HCT116 was lower compared with clinical samples. The low level of DPD activity or mRNA expression observed in these human colon carcinoma cell lines suggests that down-regulation of DPD occurs in vitro. In this model, however, up-regulation of DPD occurred during liver metastases. It became widely accepted that tumors were heterogeneous, and cells from individual tumors differed in biologic characteristics, cellular morphology, karyotype, growth rate, receptors, metabolism, and metastatic ability, even if tumors derived from one patient have the same origin or history (16). Studies have stated that some tumors arise from a small population of 'cancer stem cells,' which may be more resistant to chemotherapy and cause metastases $(35,36)$. The cancer stem cell may cause the up-regulation of DPD and resistance to 5-FU and liver metastases. Further studies are expected to provide insight on the reason for the acquisition of resistance to anticancer drugs in metastasis.

In another study, the level of TP protein in gastric and colorectal carcinoma cells was measured by ELISA and found to be significantly low (37) compared with the level in primary colorectal cancer (38). It was pointed out that predominant cells positive for TP were macrophages and other stroma cells within tumor tissues (as determined by immunohistochemistry), and the activation of fluoropyrimidines in humans might rely on the paracrine of TP by these stroma cells, but not tumor cells (39). This fact suggests that tumor cells and other cells, such as stroma and blood cells, interact with each other in vivo, and this interaction may affect the efficacy of anticancer drugs in tumor cells. Using the CDDST method, cancer cells and other cells are co-cultured in three-dimensional collagen gel droplets; these conditions may reflect in vivo circumstances. Only cancer cells are distinguished by neutral red and its computer system. CD-DST 
might be a useful sensitivity test for studying tumor cells under in vivo-like conditions

Based on results from clinical specimens and the liver metastasis model in nude mice, we conclude that DPD and TP may play a role in the acquisition of resistance to 5-FU during liver metastasis of colorectal cancer. The liver metastasis model in this study might be helpful in the investigation of mechanisms by which colorectal cancer cells acquire resistance to 5-FU during liver metastasis.

\section{References}

1. Moertel CG: Chemotherapy for colorectal cancer. N Engl J Med 330: 1136-1142, 1994.

2. Piedbois P, Buyse M, Rustum Y, Machover D, Erlichman C, Carlson RW, Valone F, Labianca R, Doroshow JH and Petrelli N: Modulation of fluorouracil by leucovorin in patients with advanced colorectal cancer: evidence in terms of response rate. The advanced colorectal cancer meta-analysis project. J Clin Oncol 10: 896-903, 1992.

3. Saltz LB, Cox JV, Blanke C, Rosen LS, Fehrenbacher L, Moore ML, Maroun JA, Ackland SP, Locker PK, Pirotta N, Elfring GL and Miller LL: Irinotecan plus fluorouracil and leucovorin for metastatic colorectal cancer. N Engl J Med 343: 905-914, 2000.

4. Johnston PG, Lenz H-J, Leichman CG, Danenberg KD, Allegra CJ, Danenberg PV and Leichman L: Thymidylate synthase gene and protein expression correlate and are associated with response to 5-fluorouracil in human colorectal and gastric tumors. Cancer Res 55: 1407-1412, 1995.

5. Salonga D, Danenberg KD, Johnson M, Metzger R, Groshen S, Tsao-Wei DD, Lenz H-J, Leichman CG, Leichman L, Diasio RB and Danenberg PV: Colorectal tumors responding to 5-fluorouracil have low gene expression levels of dihydropyrimidine dehydrogenase, thymidylate synthase and thymidine phosphorylase. Clin Cancer Res 6: 1322-1327, 2000.

6. Metzger R, Danenberg K, Leichman CG, Salonga D, Schwartz EL, Wadler S, Lenz H-J, Groshen S, Leichman L and Dannenberg PV: High basal level gene expression of thymidine phosphorylase (platelet-derived endothelial cell growth factor) in colorectal tumors is associated with nonresponse to 5-fluorouracil. Clin Cancer Res 4: 2371-2376, 1998.

7. Isshi K, Sakuyama T, Gen T, Nakamura Y, Kuroda T, Katuyama T and Maekawa Y: Predicting 5-FU sensitivity using human colorectal cancer specimens: comparison of tumor dihydropyrimidine dehydrogenase and orotate phosphoribosyl transferase activities with in vitro chemosensitivity to 5-FU. Int J Clin Oncol 7: 335-342, 2002.

8. Mader RM, Sieder AE, Braun J, Rizovski B, Kalipciyan M, Mueller MW, Jakesz R, Rainer H and Steger GG: Transcription and activity of 5-fluorouracil converting enzymes in fluoropyrimidine resistance in colon cancer in vitro. Biochem Pharmacol 54: 1233-1242, 1997

9. Cascinu S, Aschele C, Barni S, Debernardis D, Baldo C, Tunesi G, Catalano V, Staccioli MP, Brenna A, Muretto P and Catalano G: Thymidylate synthase protein expression in advanced colon cancer: correlation with the site of metastasis and the clinical response to leucovorin-modulated bolus 5-fluorouracil. Clin Cancer Res 5: 1996-1999, 1999.

10. Ishikawa Y, Kubota T, Otani Y, Watanabe M, Teramato T, Kumai K, Kitajima M, Takechi T, Okabe H and Fukushima M: Dihydropyrimidine dehydrogenase activity and messenger RNA level may be related to the antitumor effect of 5-fluorouracil on human tumor xenografts in nude mice. Clin Cancer Res 5: 883-889, 1999 .

11. Langenbach RJ, Danenberg PV and Heidelberger C: Thymidylate synthetase: mechanism of inhibition by 5-fluoro-2'-deoxyuridylate. Biochem Biophys Res Commun 48: 1565-1571, 1972 .

12. Matsuoka H, Ueo H, Sugimachi K and Akiyoshi T: Preliminary evidence that incorporation of 5-fluorouracil into RNA correlates with antitumor response. Cancer Invest 10: 265-269, 1992.

13. Naguib FNM, el Kouni MH and Cha S: Enzymes of uracil catabolism in normal and neoplastic human tissues. Cancer Res 45: 5405-5412, 1985.
14. Heggie GD, Sommadossi JP, Cross DS, Hustler WJ and Diasio RB: Clinical pharmacokinetics of 5-fluorouracil and its metabolites in plasma, urine, and bile. Cancer Res 47: 2203-2206, 1987.

15. Ichikawa W, Uetake H, Shirota Y, Yamada H, Takahashi T, Nihei Z, Sugihara K, Sasaki Y and Hirayama R: Both gene expression for orotate phosphoribosyltransferase and its ratio to dihydropyrimidine dehydrogenase influence outcome following fluoropyrimidine-based chemotherapy for metastatic colorectal cancer. Br J Cancer 89: 1486-1492, 2003.

16. Nio Y, Imai S, Shiraishi T, Tsubono M, Morimoto H, Tseng C-C and Tobe T: Chemosensitivity correlation between the primary tumors and simultaneous metastatic lymph nodes of patients evaluated by DNA synthesis inhibition assay. Cancer 65: 1273-1278, 1990.

17. Maehara Y, Sakaguchi Y, Emi Y, Kusumoto T, Kohnoe S, Mori $\mathrm{M}$ and Sugimachi K: Primary and metastatic lesions of clinical colorectal cancer differ in chemosensitivity. Int J Colorectal Dis 5: 87-89, 1990.

18. Schlag P and Schreml W: Heterogeneity in growth pattern and drug sensitivity of primary tumor and metastases in the human tumor colony-forming assay. Cancer Res 42: 4086-4089, 1982.

19. Gorlick R, Metzger R, Danenberg KD, Salonga D, Miles JS, Longo GSA, Fu J, Banerjee D, Klimstra D, Jhanwar S, Danenberg PV, Kemeny N and Bertino JR: Higher levels of thymidylate synthase gene expression are observed in pulmonary as compared with hepatic metastases of colorectal adenocarcinoma. J Clin Oncol 16: 1465-1469, 1998.

20. Aschele C, Debernardis D, Tunesi G, Maley F and Sobrero A: Thymidylate synthase protein expression in primary colorectal cancer compared with the corresponding distant metastases and relationship with the clinical response to 5-fluorouracil. Clin Cancer Res 6: 4797-4802, 2000.

21. Yamada H, Ichikawa W, Uetake H, Shirota Y, Nihei Z, Sugihara K and Hirayama R: Thymidylate synthase gene expression in primary colorectal cancer and metastatic sites. Clin Colorectal Cancer 1: 169-173, 2001.

22. Brattain MG, Fine WG, Khaled FM, Thompson J and Brattain DE: Heterogeneity of malignant cells from a human colonic carcinoma. Cancer Res 41: 1751-1756, 1981.

23. Grem JL, Danenberg KD, Behan K, Parr A, Young L, Danenberg PV, Nguyen D, Drake J, Monks A and Allegra CJ: Thymidine kinase, thymidylate synthase, and dihydropyrimidine dehydrogenase profiles of cell lines of the National Cancer Institute's anticancer drug screen. Clin Cancer Res 7: 999-1009, 2001.

24. Yang J-L, Hanley JR, Yu Y, Berney CR, Russell PJ and Crowe PJ: In vivo overexpression of c-erbB-2 oncoprotein in xenografts of mice implanted with human colon cancer lines. Anticancer Res 17: 3463-3468, 1997.

25. Kobayashi H, Tanisaka K, Doi O, Kodama K, Higashiyama M, Nakagawa H, Miyake M, Taki T, Hara S, Yasutomi M, Hanatani $\mathrm{Y}$, Kotake $\mathrm{K}$ and Kubuta T: An in vitro chemosensitivity test for solid human tumors using collagen gel droplet embedded cultures. Int J Oncol 11: 449-455, 1997.

26. Kobayashi H: Development of a new in vitro chemosensitivity test using collagen gel droplet embedded culture and image analysis for clinical usefulness. Recent Results Cancer Res 161: 48-61, 2003

27. Fu X, Besterman JM, Monosov A and Hoffman RM: Models of human metastatic colon cancer in nude mice orthotopically constructed by using histologically intact patient specimens. Proc Natl Acad Sci USA 88: 9345-9349, 1991.

28. Furukawa T, Fu X, Kubota T, Watanabe M, Kitajima M and Hoffman RM: Nude mouse models of human stomach cancer constructed using orthotopic implantation of histologically intact tissue. Cancer Res 53: 1204-1208, 1993.

29. Shirasaka T, Nakano K, Takechi T, Satake H, Uchida J, Fujioka A, Saito H, Okabe H, Oyama K, Takeda S, Uemi N and Fukushima M: Antitumor activity of $1 \mathrm{M}$ Tegafur-0.4 M 5chloro-2,4-dihydroxypyridine-1 M potassium oxonate (S-1) against human colon carcinoma orthotopically implanted into nude rats. Cancer Res 56: 2602-2606, 1996.

30. Miwa M, Ura M, Nishida M, Sawada N, Ishikawa T, Mori K, Shimma N, Umeda I and Ishituka H: Design of a novel oral fluoropyrimidine carbamate, capecitabine, which generates 5 -fluorouracil selectively in tumors by enzymes concentrated in human liver and cancer tissue. Eur J Cancer 34: 1274-1281, 1998 . 
31. Wang T-L, Diaz LA, Romans K, Bardelli A, Saha S, Galizia G, Choti M, Donehower R, Parmigiani G, Shih I-M, Kinzler KW, Iacobuzio-Donahue C, Vogelstein B, Lengauer C and Velculescu VE: Digital karyotyping identifies thymidylate synthase amplification as a mechanism of resistance to 5-fluorouracil in metastatic colorectal cancer patients. Proc Natl Acad Sci USA 101: 3089-3094, 2004.

32. Peters GJ, van Groeningen CJ, Laurensse EJ and Pinedo HM: A comparison of 5-fluorouracil metabolism in human colorectal cancer and colon mucosa. Cancer 68: 1903-1909, 1991.

33. Cao D, Russel RL, Zhang D, Leffert JJ and Pizzorno G: Uridine phosphorylase (-/-) murine embryonic stem cells clarify the key role of this enzyme in the regulation of the pyrimidine salvage pathway and in the activation of fluoropyrimidines. Cancer Res 62: 2313-2317, 2002.

34. Mcleod HL, Sludden J, Murray GI, Keenan RA, Davidson AI, Park K, Koruth M and Cassidy J: Characterization of dihydropyrimidine dehydrogenase in human colorectal tumors. Br J Cancer 77: 461-465, 1998.
35. Pardal R, Clarke MF and Morrison SJ: Applying the principles of stem-cell biology to cancer. Nat Rev 3: 895-902, 2003.

36. Kondo T, Setoguchi $\mathrm{T}$ and Taga T: Persistence of a small subpopulation of cancer stem-like cells in the C6 glioma cell line. Proc Natl Acad Sci USA 101: 781-786, 2004.

37. Ma T, Zhu Z-G, Ji Y-B, Zhang Y, Yu Y-Y, Liu B-Y, Yin H-R and Lin Y-Z: Correlation of thymidylate synthase, thymidine phosphorylase and dihydropyrimidine dehydrogenase with sensitivity of gastrointestinal cancer cells to 5-fluorouracil and 5-fluoro-2'-deoxyuridine. World J Gastroenterol 10: 172-176, 2004.

38. Nisimura G, Terada I, Kobayashi T, Ninomiya I, Kitagawa H, Fushida S, Fujimura T, Kayahara M, Shimizu K, Ohta T and Miwa K: Thymidine phosphorylase and dihydropyrimidine dehydrogenase levels in primary colorectal cancer show a relationship to clinical effects of 5'-deoxy-5-fluuorouridine as adjuvant chemotherapy. Oncol Rep 9: 479-482, 2002.

39. Griffiths L and Stratford IJ: Platelet-derived endothelial cell growth factor thymidine phosphorylase in tumor growth and response to therapy. Br J Cancer 76: 689-693, 1997. 